\title{
Monitoring the Trafficking of Adoptively Transferred Antigen- Specific CD8-Positive T Cells In Vivo, Using Noninvasive Luminescence Imaging
}

\author{
DAEJIN KIM, ${ }^{1}$ CHIEN-FU HUNG, ${ }^{1,2}$ and T.-C. WU ${ }^{1-4}$
}

\begin{abstract}
Understanding of the trafficking of antigen-specific $\mathrm{CD8}^{+} \mathrm{T}$ cells in vivo will provide insight about how our immune system controls infectious diseases and cancers. In the current study we used a luciferase-expressing human papillomavirus type 16 (HPV-16) E7-specific $\mathrm{CD8}^{+} \mathrm{T}$ cell for adoptive transfer to control E7-expressing TC-1 tumor cells. We used noninvasive luminescence imaging to monitor the trafficking of E7-specific CD8 ${ }^{+}$ $\mathrm{T}$ cells over time. We also boosted the luciferase-expressing $\mathrm{E} 7$-specific $\mathrm{CD8}^{+} \mathrm{T}$ cells in vivo, using E7-expressing vaccinia. We found that injected $\mathrm{E} 7$-specific $\mathrm{T}$ cells preferentially migrated to the E7-expressing tumor site but not to the E7-negative control tumor site, and increased in number at the tumor site over time. In addition, vaccination with E7-expressing vaccinia led to a significant increase in the number of E7-specific $\mathrm{CD8}^{+} \mathrm{T}$ cells at the tumor site, resulting in a significant antitumor effect compared with vaccination with wild-type vaccinia. Thus, our data suggest that the antitumor effects generated by adoptive transfer of E7specific $\mathrm{CD8}^{+} \mathrm{T}$ cells can be significantly enhanced by vaccination with $\mathrm{E} 7$-expressing vaccinia and that our system represents a plausible approach to investigate the trafficking and biology of antigen-specific $T$ cells in vivo.
\end{abstract}

\section{INTRODUCTION}

A DOPTIVE T CELL TRANSFER (ACT) has emerged as an important approach for cancer immunotherapy. ACT provides large numbers of highly active, tumor-specific $\mathrm{T}$ lymphocytes that target tumor cells by recognition of the tumor antigen. ACT therapy has been used for cancer immunotherapy in Epstein-Barr virus-induced posttransplantation lymphoproliferative disease and metastatic melanoma (for review, see Dudley and Rosenberg [2003] and Leen et al. [2006]). However, studies using ACT therapy have shown low clinical effectiveness due to a lack of persistence of the adoptively transferred T cells (Dudley et al., 2001). This suggests that there is a need for additional methods that optimize the antitumor immune response initiated by ACT. Previous studies that combined ACT therapy with dendritic cell vaccination have shown significantly improved antitumor responses compared with ACT therapy alone (Lou et al., 2004). This raises the possibility of seeking additional antigen-specific vaccines to boost the efficacy of ACT therapy.
Vaccinia has been shown to be an effective strategy for generating potent antigen-specific immune responses for controlling various types of cancer. The vaccinia virus, a member of the poxvirus family, is a promising vector for antigen-specific immunotherapy because of its high efficiency of infection, high levels of recombinant gene expression, and accommodation of genetic insertions of up to $30 \mathrm{~kb}$ (Moss, 1991). Vaccinia vectors have elicited potent antigen-specific, T cell-mediated immune responses and generated antitumor effects in numerous preclinical models (Ji et al., 1998; Chen et al., 2000). In addition, vaccinia vaccines have been used in several clinical trials, including trials in patients with cervical cancer (Borysiewicz et al., 1996), breast cancer (Scholl et al., 2000), advanced colorectal cancer (McAneny et al., 1996), prostate cancer (Sanda et al., 1999; Eder et al., 2000), and carcinoembryonic antigenexpressing tumors (Conry et al., 2000; Horig et al., 2000). Therefore, vaccinia may represent a plausible antigen-specific vaccine to further enhance ACT therapy, resulting in an enhanced therapeutic antitumor effect.

We have previously developed vaccinia-based vaccines tar-

${ }^{1}$ Department of Pathology, ${ }^{2}$ Department of Oncology, ${ }^{3}$ Department of Obstetrics and Gynecology, and ${ }^{4}$ Department of Molecular Microbiology and Immunology, Johns Hopkins Medical Institutions, Baltimore, MD 21231. 
geting E7 protein of human papillomavirus type 16 (HPV-16). It is now clear that cervical cancer is caused by HPV, particularly high-risk types 16 and 18 (Walboomers et al., 1999). HPV-encoded oncogenic protein, E7, is consistently expressed in HPVassociated malignancies and squamous intraepithelial lesions (SILs) and contributes to the malignant transformation of normal cells to cancer cells. Thus, E7 represents an ideal target antigen for the development of vaccines and therapeutic strategies against HPV-associated malignancies. We have previously created a vaccinia encoding HPV-16 E7 linked to the sorting signal of the lysosome-associated membrane protein type 1 (LAMP-1) to form Vac-sig/E7/LAMP-1. Vaccination with Vac-sig/E7/LAMP-1 generated strong E7-specific CD4 ${ }^{+}$and $\mathrm{CD} 8^{+} \mathrm{T}$ cell immune responses (Wu et al., 1995) as well as a potent antitumor effect against E7-expressing tumor TC-1 (Lin et al., 1996).

A significant challenge in determining the response to ACT therapy is the difficulty in assessing the trafficking of antigenspecific $\mathrm{T}$ cells as well as the therapeutic effect against tumors in vivo without killing the mice. We have introduced a noninvasive approach to monitor antigen-specific $\mathrm{CD} 8^{+} \mathrm{T}$ cell trafficking and tumor growth in mice. We employed bioluminescence imaging to characterize antigen-specific $\mathrm{CD}^{+} \mathrm{T}$ cell trafficking in mice as well as the in vivo tumor growth in mice. This approach allows us to observe the distribution of antigenspecific $\mathrm{T}$ cells over time. Thus, noninvasive luciferase imaging represents a suitable method by which to assess not only the kinetic change of tumor growth but also the kinetic distribution of $\mathrm{T}$ cells in vivo.

In the current study, we investigated the in vivo trafficking of luciferase-expressing HPV-16 E7-specific CD8 ${ }^{+} \mathrm{T}$ cells in mice challenged with E7-expressing tumors, using noninvasive bioluminescence imaging. In addition, we characterized the influence of vaccination with Vac-sig/E7/LAMP-1 on the distribution and proliferation of luciferase-expressing E7-specific $\mathrm{CD}^{+} \mathrm{T}$ cells after adoptive $\mathrm{T}$ cell transfer. We found that E7specific $\mathrm{CD} 8^{+} \mathrm{T}$ cells migrated to and proliferated in the location of E7-positive tumors but not in E7-negative tumors. We also found that treatment with $\mathrm{E} 7$-specific $\mathrm{CD} 8^{+} \mathrm{T}$ cells in mice challenged with TC-1 tumor led to slow tumor growth. Furthermore, we found that vaccination with E7-expressing vaccinia led to significantly increased $\mathrm{E} 7$-specific $\mathrm{CD} 8^{+} \mathrm{T}$ cells at loci of E7-expressing tumors and resulted in enhanced antitumor effects. Thus, adoptive transfer of antigen-specific $\mathrm{T}$ cells followed by immunization with antigen-specific vaccinia may represent a potentially plausible approach for cancer treatment. Our system represents a plausible approach to investigate the trafficking and biology of antigen-specific $\mathrm{T}$ cells in vivo.

\section{MATERIALS AND METHODS}

\section{Mice}

Female C57BL/6 mice (6 to 8 weeks old) were purchased from the National Cancer Institute (Frederick, MD). All animals were maintained in a specific pathogen-free facility of Johns Hopkins Hospital (Baltimore, MD). All animal procedures were performed according to approved protocols and in accordance with the recommendations for the proper use and care of laboratory animals (Institute of Laboratory Animal Research, 1996).

\section{Cell lines}

The production and maintenance of TC-1 cells (Lin et al., 1996) and E7-specific CD8 ${ }^{+} \mathrm{T}$ cells (Wang et al., 2000) have been described in previous papers. Firefly luciferase-expressing TC-1 cells (TC-1-LUC) and E7-specific CD8 ${ }^{+} \mathrm{T}$ cells (E7T-LUC) were generated with retrovirus carrying the luciferase gene. The retrovirus was produced with a pLuci-thy1.1 construct expressing both luciferase and thy1.1 (Hung et al., 2006). pLuci-thy1.1 was transfected into the Phoenix packaging cell line and the virion-containing supernatant was immediately passed through a $0.45-\mathrm{mm}$ (pore size) cellulose acetate syringe filter and used to infect TC- 1 and E7-specific CD8 ${ }^{+} \mathrm{T}$ cells in the presence of Polybrene $(8 \mathrm{mg} / \mathrm{ml}$; Sigma, St. Louis, MO). TC-1-LUC and E7T-LUC cells were isolated by preparative flow cytometry of stained cells with Thy 1.1 antibody (BD Biosciences, San Jose, CA), using a method similar to that described previously (Hung et al., 2006). After selection, TC-1 and TC-1-LUC cells were maintained in RPMI containing 10\% fetal calf serum (FCS) and G418 (400 $\mu \mathrm{g} / \mathrm{ml})$. E7-specific T cells and E7T-LUC cells were cultured with irradiated TC-1 cells, which express MHC class I:E7 peptide complex, in the presence of interleukin (IL)-2 (10 U/ml; eBioscience, San Diego, CA). This procedure was repeated every week.

\section{In vitro bioluminescence imaging}

For in vitro imaging, TC-1 cells and TC-1 cells expressing luciferase (TC-1-LUC) were serially diluted from $2 \times 10^{5}$ to $0.38 \times 10^{3}$ cells in complete medium into black, clear-bottomed, 96-well plates (Costar; Corning Life Sciences, Acton, MA). E7-specific CD8 ${ }^{+} \mathrm{T}$ cells and luciferase-expressing E7 $\mathrm{T}$ cells $(\mathrm{E} 7 \mathrm{~T}-\mathrm{LUC})$ were diluted from $5 \times 10^{5}$ to $0.95 \times 10^{3}$ cells in complete medium (the same as described previously). D-Luciferin (potassium salt; Xenogen/Caliper Life Sciences, Alameda, CA) at $150 \mu \mathrm{g} / \mathrm{ml}$ in medium was added to each well $7-8 \mathrm{~min}$ before imaging. The imaging time was $30 \mathrm{sec} / \mathrm{plate}$.

\section{In vivo E7T-LUC cell luminescence around tumor area}

In vivo bioluminescence imaging for E7T-LUC cells was conducted on a cryogenically cooled IVIS system (Xenogen/Caliper Life Sciences) using Living Image acquisition and analysis software (Xenogen/Caliper Life Sciences). For T cell imaging, on the day of tumor challenge, TC-1 cells were harvested by trypsinization, washed with $1 \times$ Hanks' balanced salt solution (HBSS), and finally resuspended with $1 \times$ HBSS for injection. Each mouse was challenged subcutaneously with TC- 1 cells $\left(5 \times 10^{5}\right)$ in the right flank area or left flank area. B16F10 cells $\left(4 \times 10^{5}\right)$ were injected into the other side in each experiment. Tumor growth was monitored by visual inspection and palpation for 1 week or 10 days. Tumor-bearing mice received, by intravenous administration, in vitro-activated E7T-LUC cells $\left(5 \times 10^{6} /\right.$ mouse $)$; the intensity of bioluminescence was checked before transfer of $\mathrm{T}$ cells and on days $0,1,3$, and 7 after transfer of E7T-LUC cells. Day 0 imaging was done 3 to $4 \mathrm{hr}$ later after transfer of E7T-LUC cells. D-Luciferin was dissolved to $7.5 \mathrm{mg} / \mathrm{ml}$ in phosphatebuffered saline (PBS), filter sterilized, and stored at $-80^{\circ} \mathrm{C}$. Mice were given the $\mathrm{D}$-luciferin by intraperitoneal injection (200 $\mu \mathrm{l} / \mathrm{mouse}, 75 \mathrm{mg} / \mathrm{kg}$ ) and anesthetized with isoflurane. 
Mice were then placed onto the warmed stage inside a lighttight camera box with continuous exposure to $1-2 \%$ isoflurane. Images were acquired for $5 \mathrm{~min}$, beginning 7-8 $\mathrm{min}$ after D-luciferin administration. In general, three or four mice were imaged at a time. The levels of light from the biolumi- nescent cells were detected by the IVIS camera system, integrated, and digitized. Regions of interest from displayed images were designated around the tumor sites and quantified as total photon counts, using Living Image 2.50 software (Xenogen/Caliper Life Sciences).

(A)

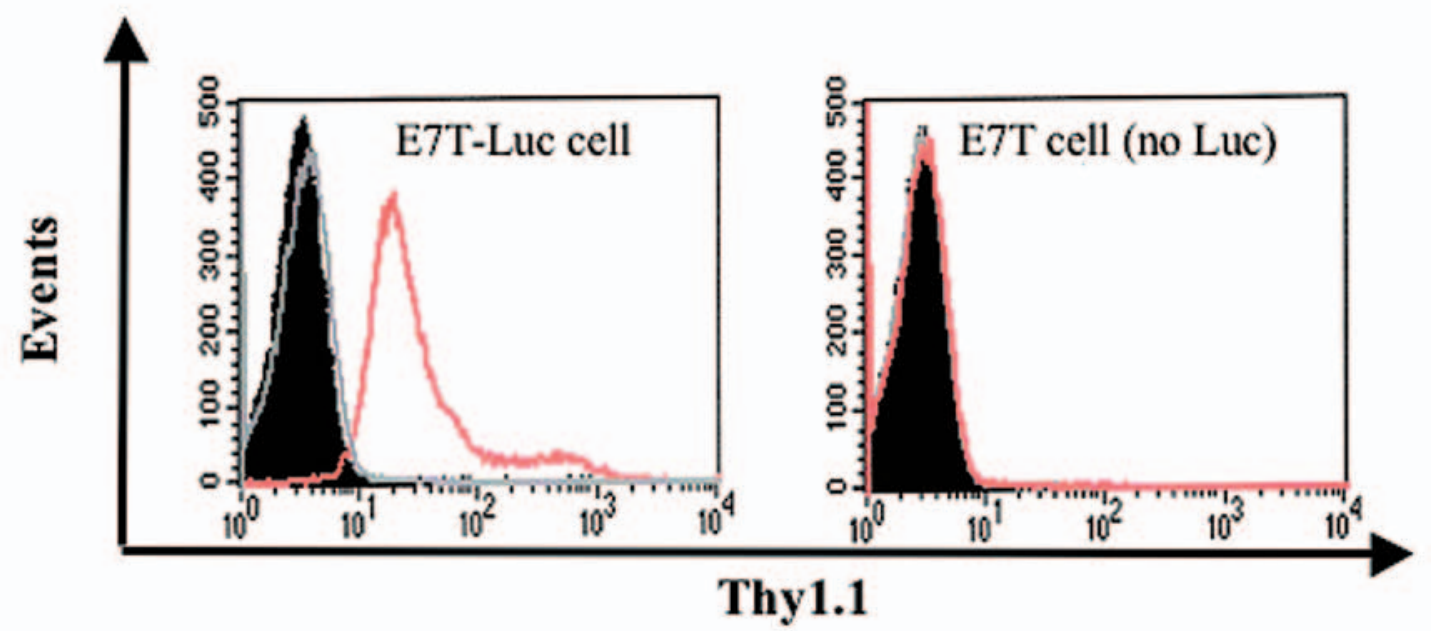

(B)

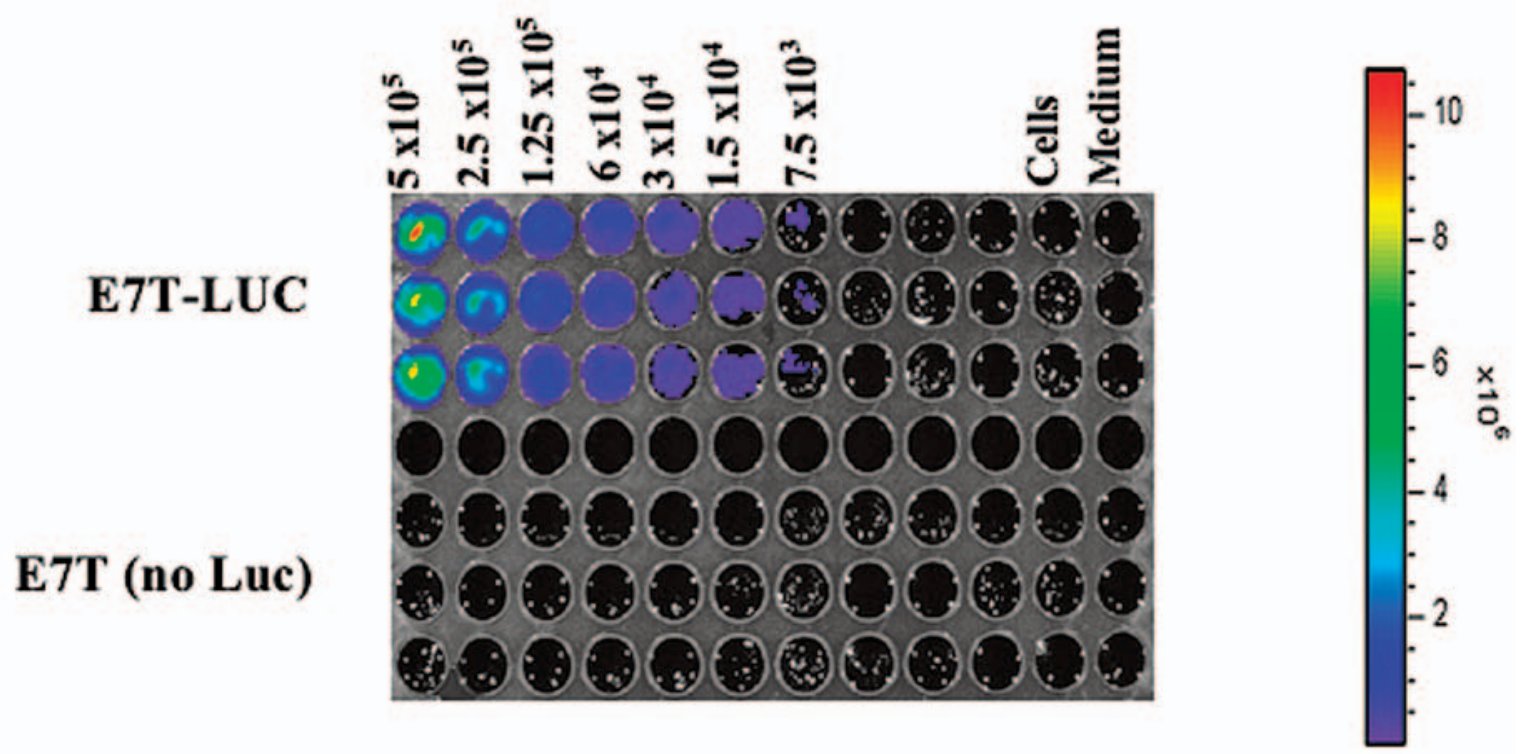

FIG. 1. Characterization of luciferase expression in E7-specific CD8 ${ }^{+} \mathrm{T}$ cells transduced with retrovirus encoding luciferase. Luciferase-expressing E7-specific $\mathrm{CD}^{+} \mathrm{T}$ cells (E7T-LUC) were generated by transduction with retrovirus expressing both luciferase and Thy 1.1. The cells were then characterized by flow cytometric analysis and bioluminescence imaging. (A) Flow cytometric analysis demonstrating Thy1.1 expression in E7T-LUC cells (left). E7T cells not transduced with luciferase-expressing retrovirus (right) were used as a negative control. (B) Luminescence images of 96-well plates containing E7T-LUC cells at 1:2 serial dilutions. E7T cells not transduced with the luciferase-expressing retrovirus were used as a control. 
Adoptive immunotherapy combined with or without vaccination

The therapeutic efficacy of E7-specific T cells expanded with IL-2 $(10 \mathrm{U} / \mathrm{ml})$ for 5 days was assessed in TC-1-LUC cell-bearing mouse models. TC-1-LUC cells $\left(2 \times 10^{4}\right)$ suspended in 200 $\mu \mathrm{l}$ of HBSS were injected subcutaneously into the right hind leg area. Three days later, mice were injected intravenously with in vitro-activated $\mathrm{E} 7$-specific $\mathrm{CD} 8^{+} \mathrm{T}$ cells $\left(5 \times 10^{6}\right)$. Images were taken according to the previously described time schedule. An acquisition time of $30 \mathrm{sec}$ was used for in vivo bioluminescence, depending on the time point.

To check the effect on proliferation of adoptively transferred $T$ cells combined with vaccination, subcutaneous tumors were established by injecting $1 \times 10^{4}$ TC- 1 cells in $200 \mu$ of HBSS into the right hind leg area. One week later, mice received E7TLUC cells $\left(5 \times 10^{6}\right)$ intravenously, followed by determination of bioluminescence (at indicated time point). Each mouse group for combined immunotherapy was vaccinated with wild-type vaccinia or Vac-sig/E7/LAMP-1 via the intraperitoneal route 1 week after the transfer of $\mathrm{T}$ cells, and then noninvasive, realtime in vivo imaging of the animals was performed on days 0 , 1,3 , and 7 after vaccination with vaccinia. Vaccinia D0 (T7) imaging was performed 3 to $4 \mathrm{hr}$ after intraperitoneal injection of vaccinia. The generation of wild-type vaccinia and Vacsig/E7/LAMP-1 was described previously (Wu et al., 1995). The viral stock was preserved at $-70^{\circ} \mathrm{C}$ before vaccination. Before use, the virus was thawed, sonicated in liquid phase for 30 sec, trypsinized with trypsin-EDTA in a $37^{\circ} \mathrm{C}$ water bath for $30 \mathrm{~min}$, and diluted with minimal essential medium containing $2.5 \%$ fetal bovine serum to a final concentration of $1 \times 10^{8}$ plaque-forming units $(\mathrm{PFU}) / \mathrm{ml}$. Each mouse was vaccinated with $1 \times 10^{7} \mathrm{PFU}$ of vaccinia $(0.1 \mathrm{ml}$ of the diluted vaccine) via the intraperitoneal route. Tumor growth was measured twice a week with Vernier calipers and recorded as tumor volume $\left(\mathrm{mm}^{3}\right)$. In each adoptive transfer experiment, tumor-bearing mice were pooled and randomly distributed to control and treatment groups.

\section{Tumor measurement and conditional survival}

Three-dimensional tumor sizes were measured twice or three times per week with Vernier calipers. Tumor sizes were approximated by multiplying the measured lengths. Beginning on day 25 after challenge with tumor cells, tumors were measured every other day, and mice with tumor sizes $>19 \mathrm{~mm}$ in diameter or projected tumor volumes $>10 \%$ body weight (or $>2700$ $\mathrm{mm}^{3}$ ) were considered moribund and killed. Tumor volume was calculated according to the following formula: $V=(L \times W \times$
$D$ ), where $V$ is tumor volume, $L$ is length, $W$ is width, and $D$ is depth. All the animal studies were approved by the Institutional Animal Care and Use Committee at Johns Hopkins Hospital (Baltimore, MD).

\section{Statistical analysis}

All data, expressed as means $\pm \mathrm{SD}$, are representative of at least two independent experiments. Data for intensity of bioluminescence and tumor treatment experiments were analyzed by analysis of variance (ANOVA). Comparisons between individual data points were made by Student $t$ test. Kaplan-Meier survival curves for tumor treatment experiments were applied. To determine the significance of differences between curves, $p$ values were calculated by log-rank test. $p<0.05$ was considered significant.

\section{RESULTS}

\section{E7-specific $C D 8^{+} T$ cell line transduced with retrovirus encoding luciferase leads to expression of luciferase}

To create a noninvasive imaging system that we could use to characterize the location of $\mathrm{E} 7$-specific $\mathrm{CD}^{+}{ }^{+} \mathrm{T}$ cells in vivo, we generated a luciferase-expressing E7-specific $\mathrm{CD} 8^{+} \mathrm{T}$ cell line by transducing an E7-specific $\mathrm{CD}^{+} \mathrm{T}$ cell line (E7T) with retrovirus encoding luciferase and Thy 1.1. Thy1.1 allowed us to select the E7-specific $\mathrm{CD}^{+}{ }^{+} \mathrm{T}$ cells successfully transduced with the retrovirus, using a preparatory sorter. As shown in Fig. 1A, almost all E7-specific $\mathrm{CD}^{+} \mathrm{T}$ cells transduced with retrovirus encoding luciferase and Thy1.1 (E7T-LUC) express Thy1.1 (Fig. 1A, left). In comparison, E7T cells not transduced with the retrovirus show no expression of Thy1.1 (Fig. 1A, right). Luciferase expression of the E7T-LUC cells was also characterized by bioluminescence imaging. As shown in Fig. 1B, the E7T-LUC cells expressed luciferase. In contrast, E7T cells did not express luciferase. Furthermore, the intensity of luminescence correlates with the number of luciferase-expressing E7-specific $\mathrm{CD}^{+} \mathrm{T}$ cells. Thus our data indicate that E7specific $\mathrm{CD}^{+} \mathrm{T}$ cells transduced with retrovirus encoding luciferase leads to expression of luciferase.

\section{E7-specific $\mathrm{CD}^{+} \mathrm{T}$ cells migrate to and proliferate in the location of E7-expressing tumors}

To determine whether luciferase-expressing E7-specific $\mathrm{CD}^{+} \mathrm{T}$ cells can migrate to and proliferate in the location of

FIG. 2. Characterization of luciferase-expressing E7-specific CD8 ${ }^{+} \mathrm{T}$ cells in TC-1 tumor-challenged mice, using luminescence imaging. C57BL/6 mice (five per group) were subcutaneously challenged via the right hind leg with $5 \times 10^{5}$ tumor cells per mouse. One week later, TC-1 tumor-bearing mice were administered $5 \times 10^{6}$ E7T-LUC cells per mouse via the tail vein. Mice were imaged with the IVIS imaging system 200 series. Bioluminescence signals were acquired for 5 min 1 day before T cell treatment and on days 0, 1, 3, and 7 after treatment. (A) Representative luminescence images of tumor-bearing mice 1 day before and on days 0 and 7 after adoptive transfer treatment with E7T-LUC cells (right). Naive mice with adoptively transferred E7T-LUC cells were used as a control (middle). In addition, TC-1 tumor-bearing mice not receiving adoptively transferred E7TLUC cells were used as a control (left). (B) Line graph depicting the kinetic expression of luciferase (mean \pm SD) over a period of 7 days in the various groups of mice: TC-1 tumor-challenged mice without treatment with E7T-LUC cells (open circles), naive mice that were treated with E7T-LUC cells (open triangles), and TC-1-challenged mice that were treated with E7T-LUC cells (solid circles). 


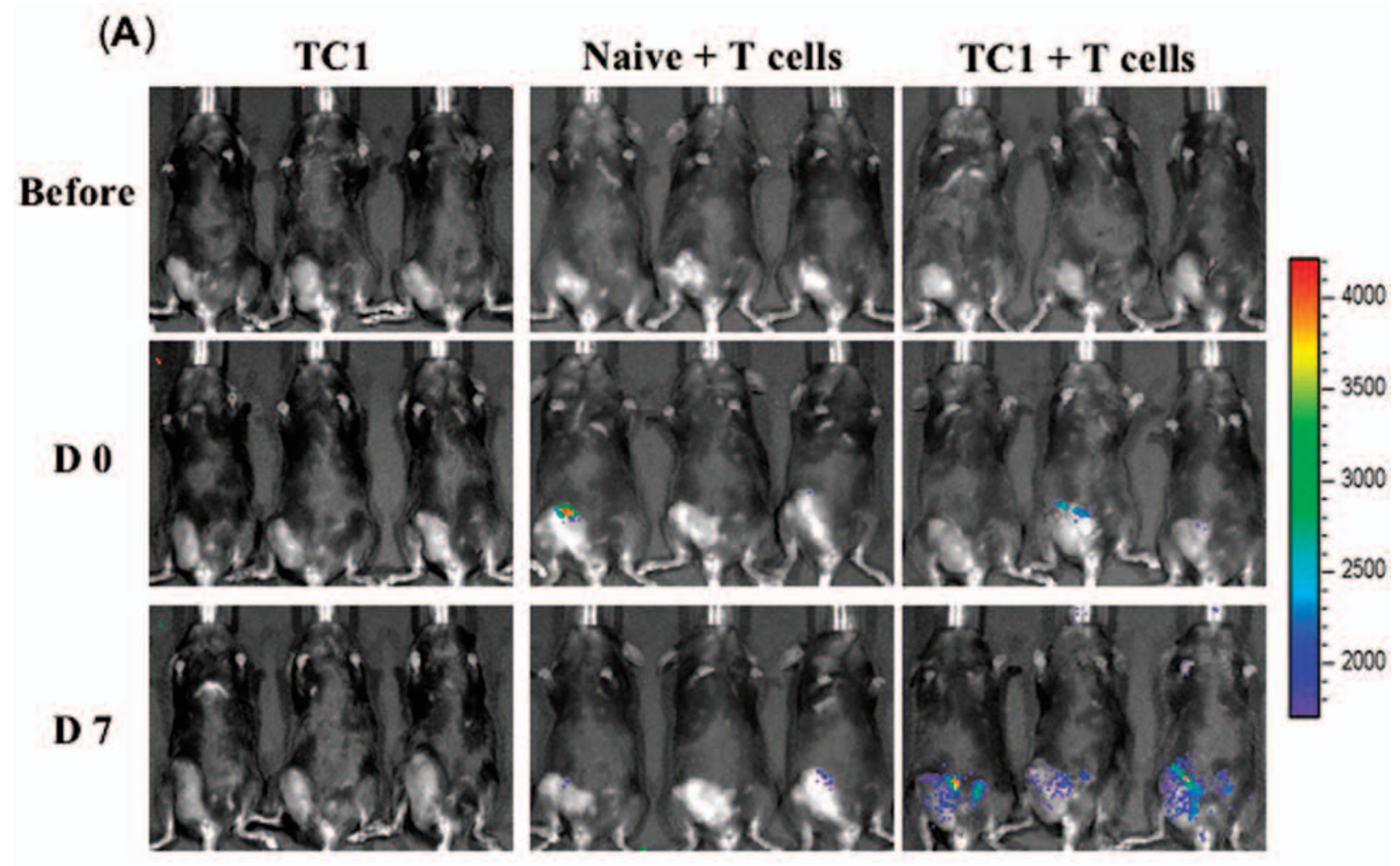

(B)

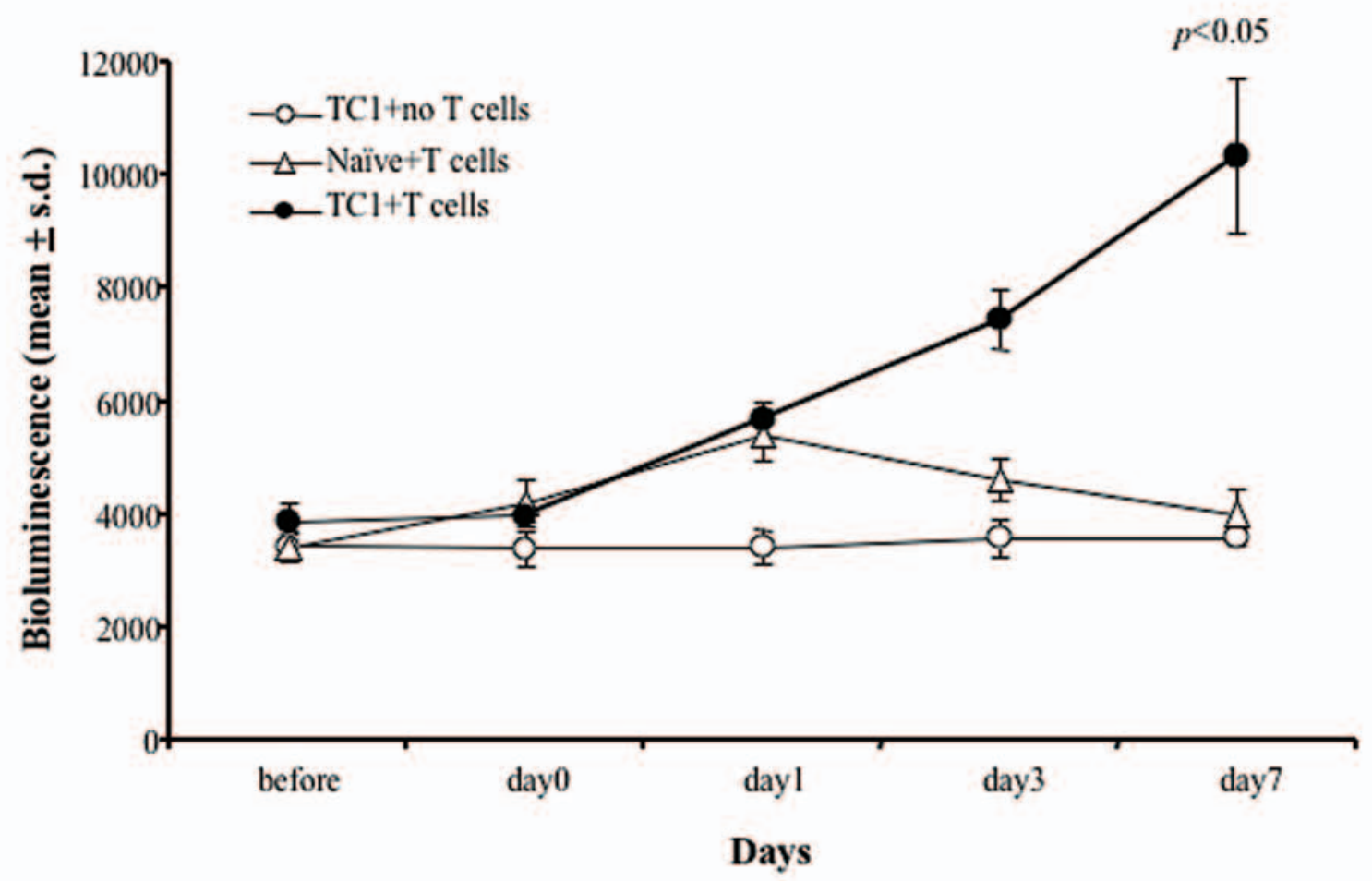


TC-1 tumor cells that express E7 in tumor-challenged mice, we performed adoptive $\mathrm{T}$ cell transfer experiments, using E7TLUC cells in mice with established TC-1 tumors. C57BL/6 mice (five per group) were subcutaneously challenged with $5 \times 10^{5}$ TC-1 tumor cells per mouse. One week later, the tumor-challenged mice were administered $5 \times 10^{6}$ E7T-LUC cells per mouse via the tail vein. As a control, a group of naive mice were administered $5 \times 10^{6}$ E7T-LUC cells per mouse via the tail vein. The location as well as the number of E7T-LUC cells were characterized by bioluminescence imaging. We also included a group of TC-1-challenged mice without T cell transfer as a control for luminescence background. As shown in Fig. 2A, there were significantly more E7T-LUC cells at the site of TC-1 tumor cells in challenged mice on day 7 compared with naive mice. The luminescence activity of the E7T-LUC cells in tumor-challenged mice and naive mice was quantified in the form of line graphs (Fig. 2B). There was a gradual increase in luminescence activity over time in the tumor-challenged mice injected with E7T-LUC cells. In comparison, naive mice injected with E7T-LUC cells failed to show a significant increase in luminescence activity over time. Thus, our data suggest that E7T-LUC cells migrate to and proliferate in the location of E7expressing TC-1 tumors.

E7T-LUC cells migrate to and proliferate in E7-expressing TC-1 tumors but not in E7-negative B16F10 tumors

To determine whether E7T-LUC cells preferentially migrate to and/or proliferate in E7-expressing TC-1 tumors, we performed adoptive $\mathrm{T}$ cell transfer experiments using mice with established E7-expressing TC-1 tumors and E7-negative B16F10 tumors. C57BL/6 mice (five per group) were subcutaneously challenged with $5 \times 10^{5}$ TC-1 cells per mouse via the left hind leg and $4 \times 10^{5}$ B16F10 cells per mouse via the right hind leg. One week later, the tumor-challenged mice were administered $5 \times 10^{6}$ E7T-LUC cells per mouse. The location as well as the number of E7T-LUC cells were characterized by bioluminescence imaging. As shown in Fig. 3A, there were significantly more E7T-LUC cells in tumor-challenged mice at the site of the TC-1 tumor (left leg) compared with E7T-LUC cells at the site of the B16F10 tumors (right leg). The luciferase activity of E7T-LUC cells in the tumor-challenged mice was quantified in the form of line graphs (Fig. 3B). A gradual increase in the luminescence activity of E7T-LUC cells was observed in the TC-1 tumors over time. In comparison, no detectable increase in the luminescence activity of E7T-LUC cells was observed in the B16F10 tumors. Thus, our data suggest that E7T-LUC cells in tumor-challenged mice preferentially migrate to and proliferate in E7-expressing TC-1 tumors compared with E7-negative tumors.

\section{Treatment with E7T cells in mice challenged with TC-1-LUC cells leads to slower tumor growth}

To generate a luciferase-expressing E7-positive tumor model for noninvasive bioluminescence imaging in vivo, we created a luciferase-expressing TC-1 tumor cell line (TC-1-LUC) by transduction with retrovirus encoding luciferase. As shown in Fig. 4A, TC-1-LUC cells expressed luciferase. In contrast, TC-
1 cells did not express luciferase. In addition, the intensity of luminescence correlated with the number of luciferase-expressing TC-1 tumor cells. Thus, we have created a luciferaseexpressing TC-1 tumor cell line that allows us to monitor in vivo tumor growth noninvasively by luminescence imaging.

To determine whether administration of E7T cells to TC-1LUC tumor-challenged mice inhibits tumor growth, we performed in vivo tumor treatment experiments with TC-1-LUC cells. C57BL/6 mice (five per group) were injected subcutaneously with $2 \times 10^{4}$ TC-1-LUC cells per mouse. Three days after tumor challenge, tumor-bearing mice were administered E7T cells via the tail vein at a dose of $5 \times 10^{6}$ cells per mouse. Tumor-challenged mice without E7T cell treatment were used as a control. Tumor growth in challenged mice was monitored by bioluminescence imaging. As shown in Fig. 4B, tumor-challenged mice treated with E7T cells showed a significant reduction in luciferase activity in comparison with tumor-challenged mice not treated with E7T cells. Luciferase activity of the TC-1-LUC cells was quantified in the form of line graphs (Fig. 4C). Greater luciferase activity was observed in tumorchallenged mice without E7T treatment compared with tumorchallenged mice receiving E7T treatment. Tumor volume was determined by Vernier caliper measurements and plotted in a line graph. As shown in Fig. 4D, significantly higher tumor volume was observed over time in TC-1-LUC tumor-challenged mice without E7T cell treatment compared with those receiving E7T cell treatment. Furthermore, we observed that the volume of TC-1-LUC tumors appeared to correlate with the intensity of luminescence of the luciferase-expressing TC-1-LUC tumors. Thus, our data indicate that treatment with E7T cells significantly inhibits tumor growth in TC-1-LUC tumor-challenged mice.

\section{Vaccination with E7-expressing vaccinia induces significant proliferation of E7T-LUC cells at E7-expressing tumors and leads to enhanced antitumor effect}

We further determined whether vaccination with E7-expressing vaccinia (Vac-sig/E7/LAMP-1) can induce proliferation of transferred E7-specific $\mathrm{CD} 8^{+} \mathrm{T}$ cells and result in an enhanced antitumor effect against E7-expressing tumors (TC1). C57BL/6 mice (five per group) were injected subcutaneously with $1 \times 10^{4} \mathrm{TC}-1$ cells per mouse. One week after tumor challenge, tumor-bearing mice were treated with E7TLUC cells at a dose of $5 \times 10^{6}$ cells per mouse, or remained untreated. One week after $\mathrm{T}$ cell treatment, the $\mathrm{T}$ cell-treated mice were intraperitoneally vaccinated with either wild-type vaccinia or Vac-sig/E7/LAMP-1. TC-1-challenged mice that were treated with E7T-LUC cells but not vaccinated were used as a control. The quantification and location of E7T-LUC cells were characterized by bioluminescence imaging. Luminescence images of representative mice are shown in Fig. 5A. A significantly higher intensity of luminescence was observed at the location of TC-1 tumors in challenged mice vaccinated with Vac-sig/E7/LAMP-1 (Fig. 5A, right) compared with challenged mice vaccinated with wild-type vaccinia (Fig. 5A, middle). No significant difference in the intensity of luminescence was observed in TC-1 tumor-challenged mice with- 
(A)

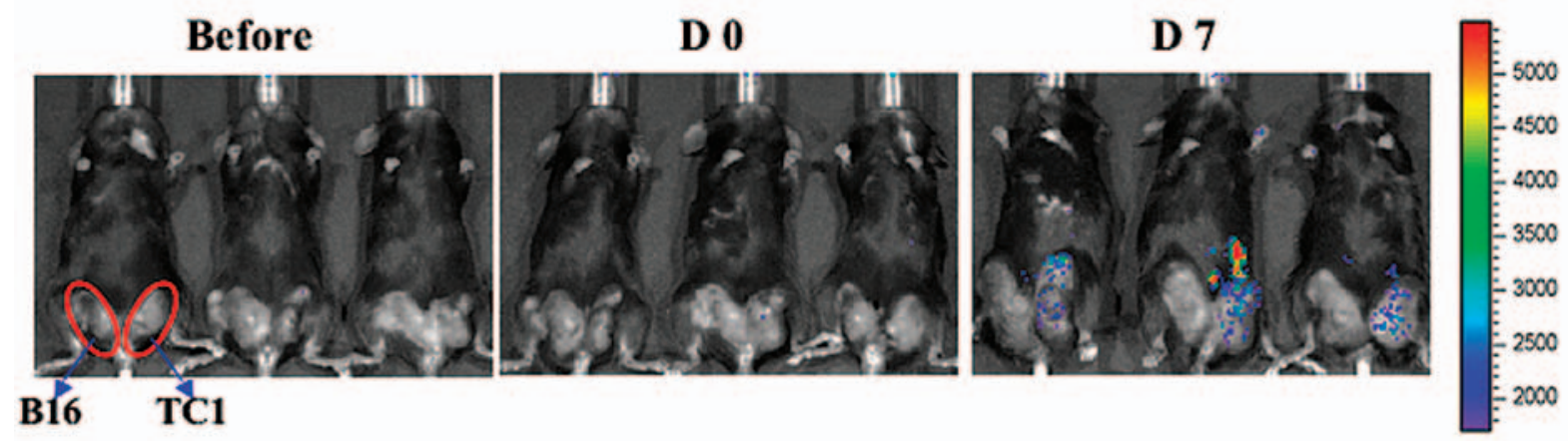

(B)

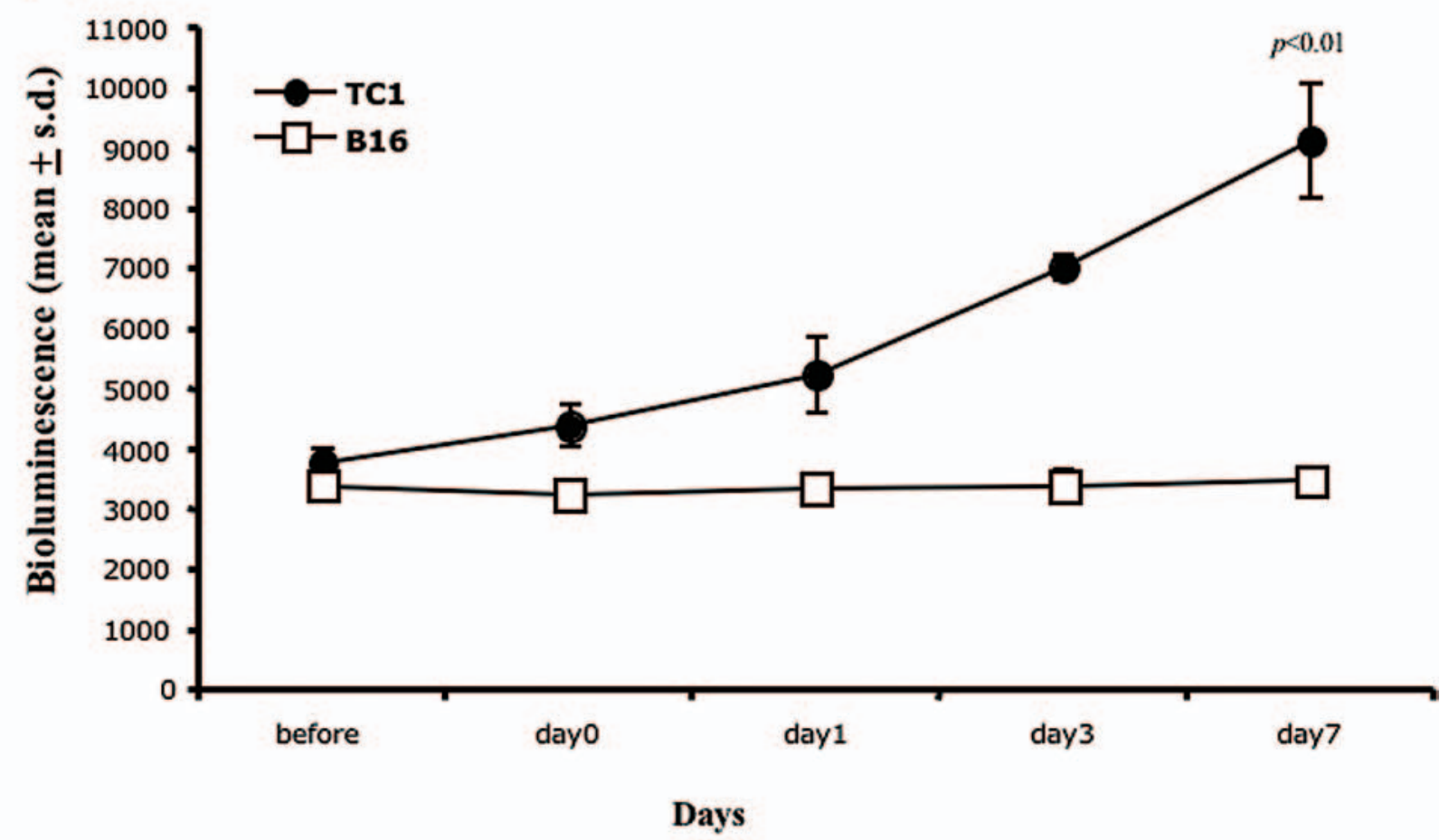

FIG. 3. Characterization of luciferase-expressing E7-specific CD ${ }^{+} \mathrm{T}$ cells in TC-1 and B16F10 tumor-challenged mice using luminescence imaging. C57BL/6 mice (five per group) were subcutaneously injected with TC-1 cells in the left hind leg and B16F10 cells in the right hind leg. One week later, TC-1 tumor-bearing mice were administered E7T-LUC cells at a dose of $5 \times$ $10^{6}$ cells per mouse via the tail vein. Mice were imaged with the IVIS Imaging System Series 200. Bioluminescence signals were acquired for 5 min 1 day before treatment, and days $0,1,3$, and 7 after $\mathrm{T}$ cell treatment. (A) Representative luminescence images of tumor-bearing mice 1 day before, day 0 , and day 7 after adoptive treatment of E7T-LUC cells. Red circles indicate the location of the tumors in challenged mice. (B) Line graph depicting the kinetic expression of luciferase (mean \pm SD) over a period of 7 days in mice challenged with B16F10 (open square) and TC-1 cells (closed circle) and treated with E7T-LUC cells.

out vaccination (Fig. 5A, left) compared with TC-1 tumorchallenged mice wild-type vaccinia vaccination (Fig. 5A, middle). Bar graphs showing the average intensity of luminescence imaging are presented in Fig. 5B. Vaccination with Vac-sig/E7/LAMP-1 caused the highest intensity of lumines- cence during the initial 3 days after vaccination. Taken together, our data suggest that vaccination of TC-1 tumor-challenged mice with E7-expressing vaccinia induces the proliferation of transferred $\mathrm{E} 7$-specific $\mathrm{CD} 8^{+} \mathrm{T}$ cells at the location of E7-expressing TC-1 tumors. 
(A)

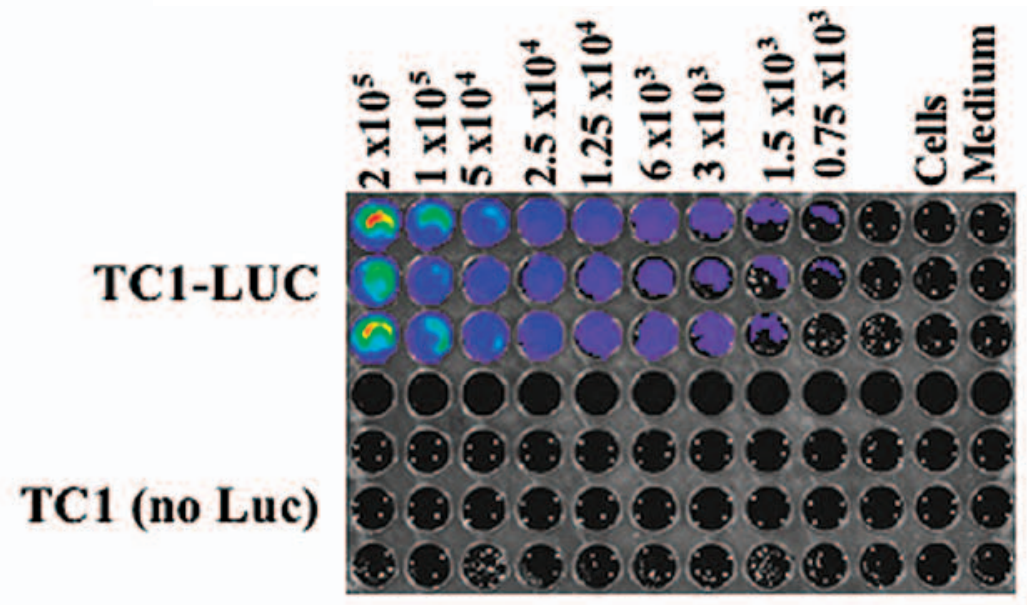

(B)

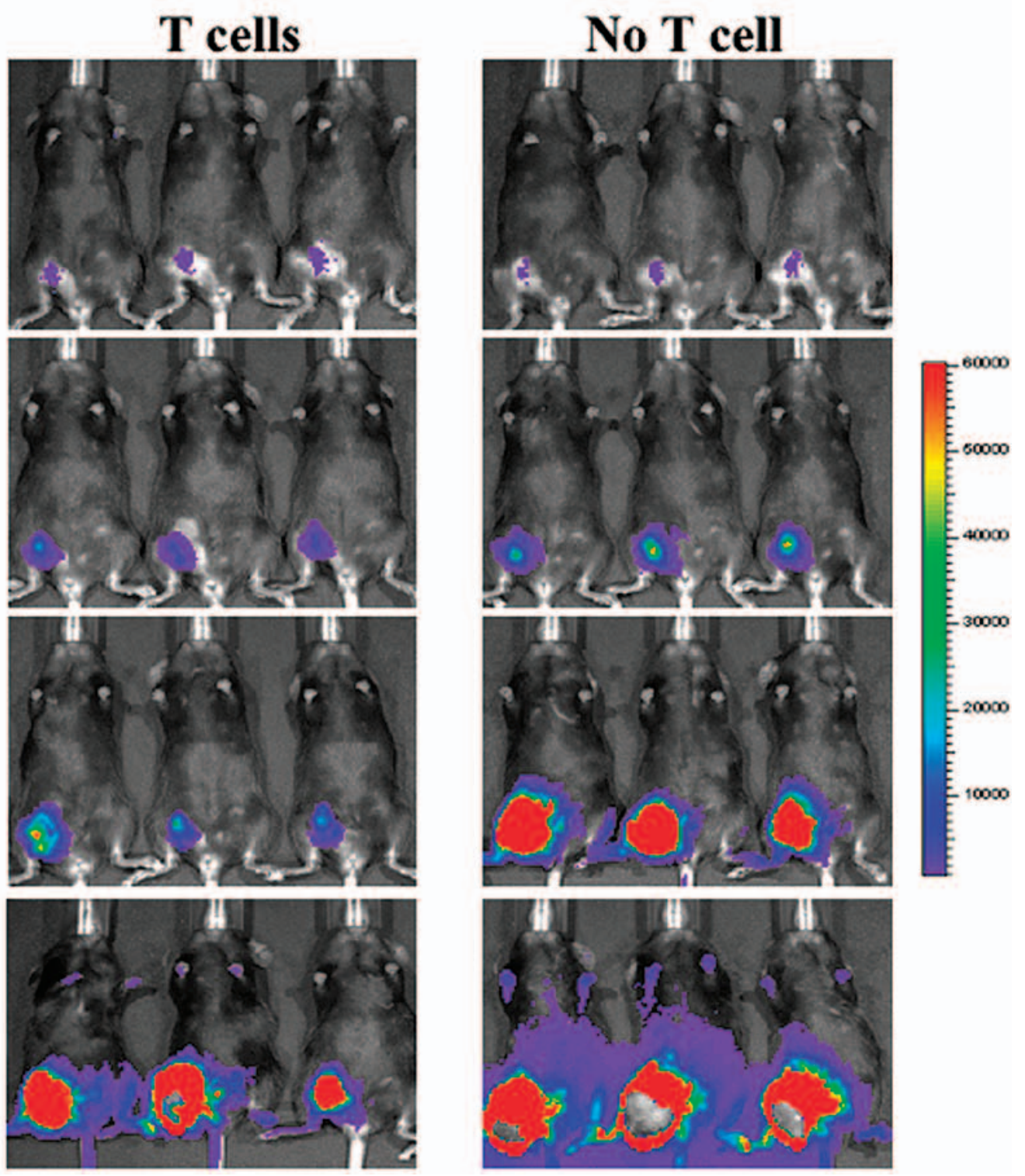

FIG. 4A and B. 
(C)
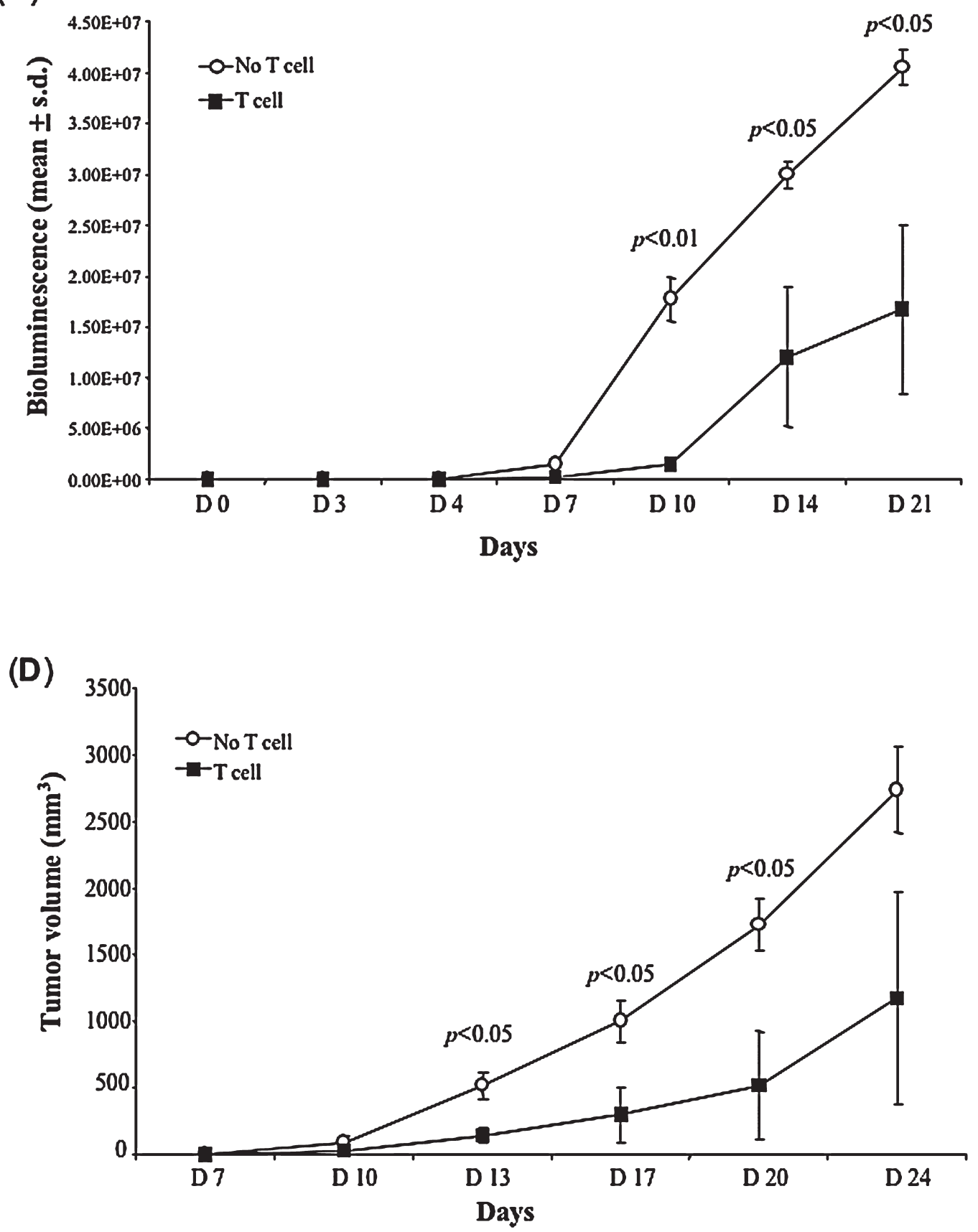

FIG. 4. In vivo tumor treatment experiment with E7T cells using luciferase-expressing TC-1 tumor cells. Luciferase-expressing TC-1 tumor cells (TC-1-LUC) were generated by transduction with lentivirus expressing luciferase. (A) Luminescence images of 96-well plates containing TC-1-LUC cells at 1:2 serial dilutions. TC-1 cells not transduced with luciferase-expressing lentivirus were used as a control. (B) Representative luminescence images of TC-1-LUC-challenged mice. C57BL/6 mice (five per group) were subcutaneously challenged with $2 \times 10^{4} \mathrm{TC}-1-\mathrm{LUC}$ cells per mouse via the right hind leg. Three days later, TC1 tumor-bearing mice were either treated with E7T cells at a dose of $5 \times 10^{6}$ cells per mouse via the tail vein (left) or not treated (right). Mice were imaged with the IVIS imaging system 200 series. Bioluminescence signals were acquired for 30 sec. (C) Line graph depicting the kinetic expression of luciferase (mean $\pm \mathrm{SD}$ ) over a period of 21 days in TC-1-LUC tumor-bearing mice treated with E7T cells (solid squares) or not treated with E7T cells (open circles). (D) Line graph depicting tumor volume (mean \pm $\mathrm{SD}$ ) in TC-1 tumor-bearing mice treated with E7T cells (solid squares) or not treated with E7T cells (open circles). Tumor volume was measured starting from day 7. 
(A)

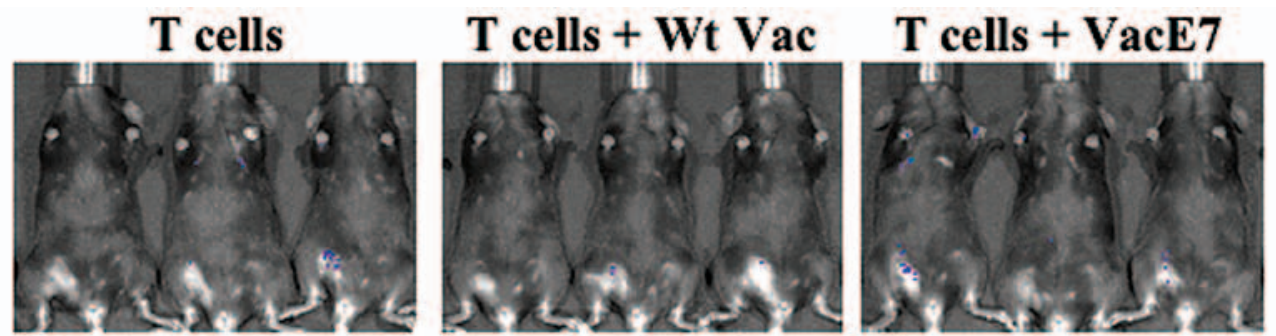

T 3
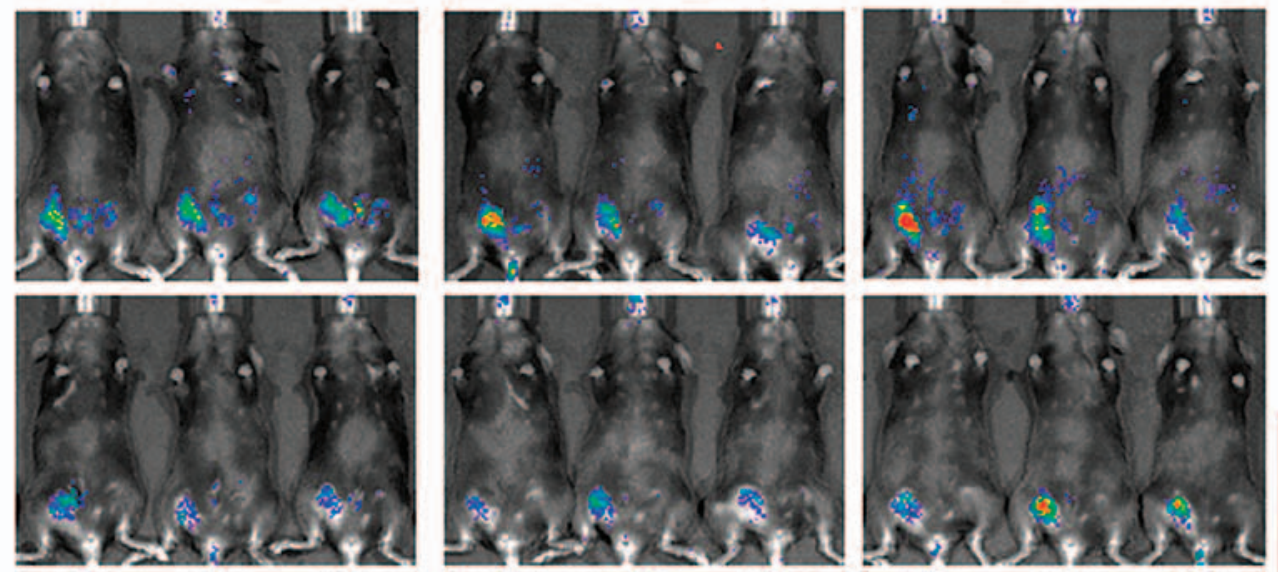

T 7

(vaccinia D0)

T 8
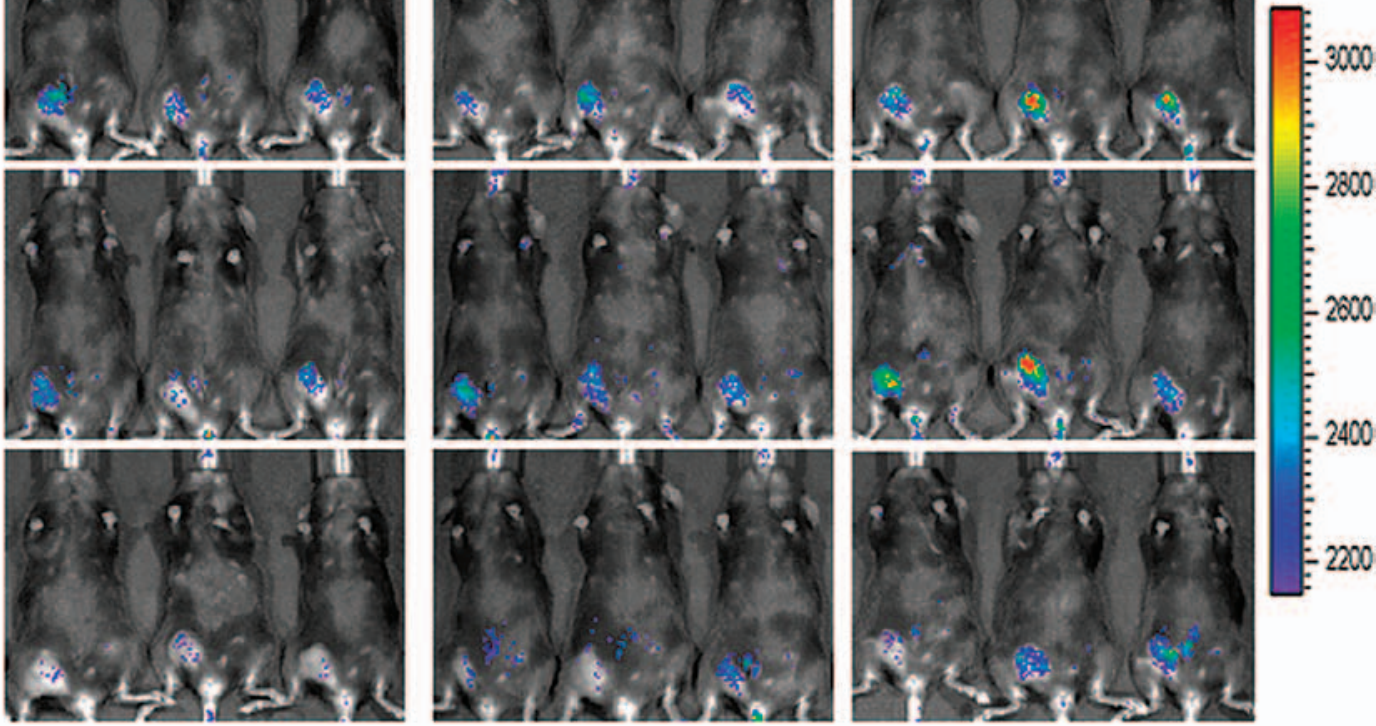

T 10

(B)

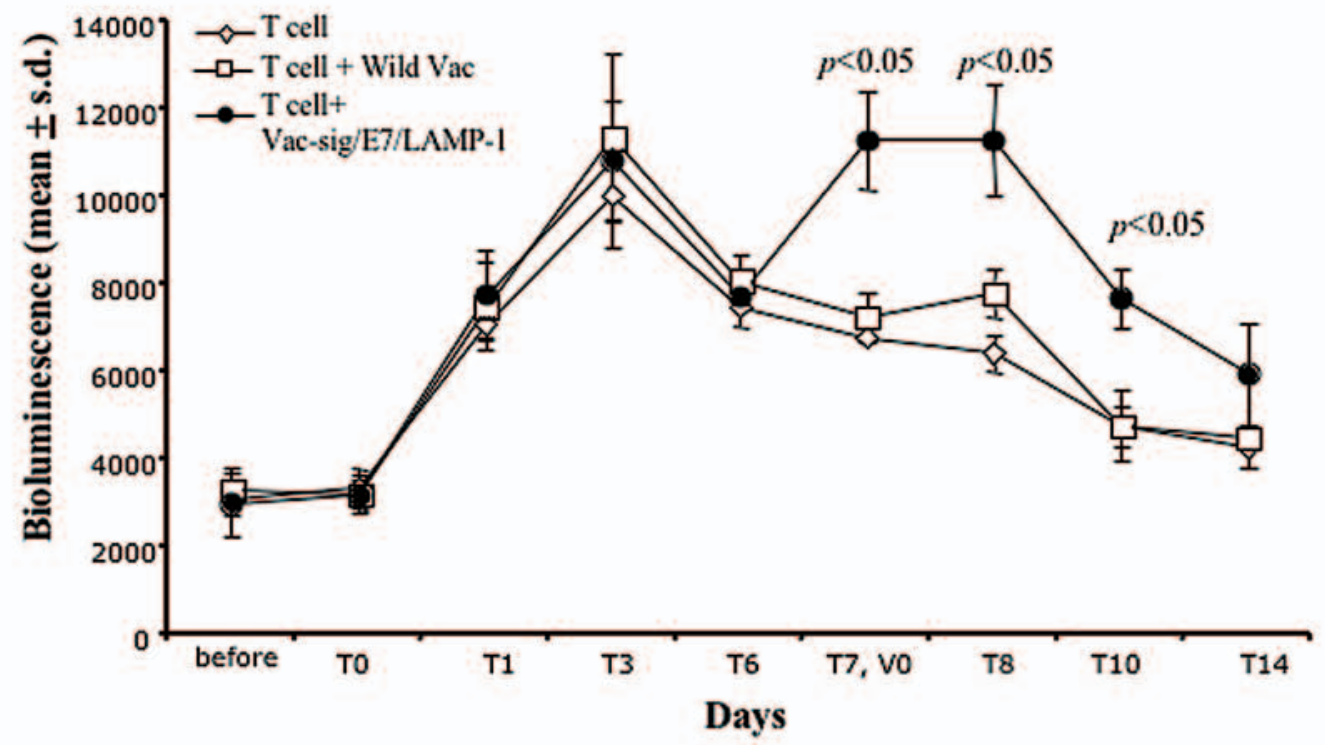


Vaccination with E7-expressing vaccinia induces enhanced antitumor effect generated by adoptive transfer of E7-specific CD ${ }^{+} T$ cells

We further determined whether vaccination with Vacsig/E7/LAMP-1 enhanced antitumor effects as well as improved the survival of E7-expressing TC-1 tumor-challenged mice that received adoptively transferred luciferase-expressing E7-specific $\mathrm{CD}^{+}{ }^{+} \mathrm{T}$ cells (E7T-LUC). TC-1 tumor-challenged C57BL/6 mice underwent adoptive transfer of E7T-LUC cells followed by vaccination with Vac-sig/E7/LAMP-1 or wild-type vaccinia, similar to what we described previously in Fig. 5. We also included tumor-challenged mice treated with adoptively transferred T cells alone or Vac-sig/E7/LAMP-1 alone as controls. Tumor volume was determined by Vernier caliper measurements and plotted in a line graph. As shown in Fig. 6A, treatment by adoptive T cell transfer followed by vaccination with Vac-sig/E7/LAMP-1 vaccinia generated the best antitumor effects in TC-1 tumor-challenged mice. Tumor-challenged mice treated with Vacsig/E7/LAMP-1 vaccinia alone also generated a significantly better antitumor effect compared with mice treated by adoptive $\mathrm{T}$ cell transfer alone, although the degree of antitumor effect was not as good as treatment by adoptive $\mathrm{T}$ cell transfer followed by vaccination with Vac-sig/E7/LAMP-1. Treatment of tumor-challenged mice by adoptive $T$ cell transfer followed by vaccination with wild-type vaccinia generated a similar antitumor effect compared with tumor-challenged mice treated by adoptive $\mathrm{T}$ cell transfer alone. These data indicate that the observed enhancement of E7 antigen-specific $\mathrm{CD}^{+}{ }^{+} \mathrm{T}$ cells by vaccination with E7-expressing vaccinia (see Fig. 5) can result in potent therapeutic antitumor effects against E7-expressing tumors. We further characterized the survival of tumor-challenged mice by Kaplan-Meier survival analysis. As shown in Fig. 6B, we observed significantly prolonged survival of TC-1 tumor-challenged mice that received both adoptive $\mathrm{T}$ cell transfer and vaccination with Vac-sig/E7/LAMP-1 compared with mice that underwent the other treatments. Taken together, treatment of E7-expressing TC1 tumor-challenged mice receiving adoptive transfer of E7-specific $\mathrm{CD}^{+} \mathrm{T}$ cells and Vac-sig/E7/LAMP-1 vaccinia enhanced the antitumor effect generated by adoptive $\mathrm{T}$ cell immunotherapy as well as significantly prolonged the survival of tumor-challenged mice.

\section{DISCUSSION}

In the current study, we used noninvasive bioluminescence imaging to investigate the in vivo trafficking and possible an- titumor effect of adoptively transferred HPV-16 E7-specific $\mathrm{CD}^{+} \mathrm{T}$ cells in mice challenged with E7-expressing tumors. We found that $\mathrm{E} 7$-specific $\mathrm{CD} 8^{+} \mathrm{T}$ cells migrated to and proliferated in the location of E7-positive tumors but not in E7negative tumors and generated an antitumor effect. We also found that vaccination with E7-expressing vaccinia induced significant proliferation of E7-specific $\mathrm{CD}^{+} \mathrm{T}$ cells at loci of E7expressing tumors and resulted in enhanced antitumor effects generated by ACT therapy. Thus, adoptive transfer of antigenspecific $\mathrm{T}$ cells followed by immunization with antigen-specific vaccinia represents a potentially promising approach for the control of cancer.

In our study, we observed a significant increase in the number of E7-specific CD8 ${ }^{+} \mathrm{T}$ cells at the location of E7-expressing tumors after tail vein injection. Such results may be attributed to the homing and/or retention of E7-specific T cells to the site of E7-expressing tumors. Furthermore, T cell proliferation at the location of E7-expressing tumors may also contribute to the observed increase in the number of E7-specific $\mathrm{CD}^{+} \mathrm{T}$ cells at E7-expressing tumors. The expression of E7 antigen in tumors is clearly important for the observed phenomenon, because we do not see any significant increase in the number of E7-specific CD ${ }^{+} \mathrm{T}$ cells at the site of E7-negative tumors.

In vivo imaging of luciferase-expressing antigen-specific $\mathrm{T}$ cells by noninvasive bioluminescence represents an effective approach to study $\mathrm{T}$ cell biology in vivo. For example, molecules that are crucial for $\mathrm{T}$ cell homing, activation, proliferation, or tumor infiltration can be potentially modified in the luciferase-expressing antigen-specific $\mathrm{T}$ cells and compared with unmodified parental $\mathrm{T}$ cells in vivo for their functional variation (such as migration, proliferation, or aggregation), using noninvasive luminescence imaging over time. In addition, the imaging system can be used to study the influence of various vaccination strategies on the biology of the antigen-specific $\mathrm{T}$ cells in vivo over time (Figs. 5 and 6). It is conceivable that such technology will be more extensively used for the study of $\mathrm{T}$ cell biology in vivo in future.

One of the major limitations of ACT therapy is that the antigen-specific T cells do not persist over time. ACT therapy led to some therapeutic effect, but usually failed to control tumor growth completely. A potential method to overcome this limitation is to perform repeated $\mathrm{T}$ cell transfers. Another potential approach to boost the therapeutic effect of ACT therapy is to combine $\mathrm{T}$ cell transfer with active vaccination with an antigen-specific vaccine such as antigen-loaded dendritic cells or vaccinia virus encoding the antigen. For example, in the aforementioned study done by Lou et al. (2004), adoptive transfer

FIG. 5. Characterization of luciferase-expressing E7-specific CD8 ${ }^{+} \mathrm{T}$ cells in $\mathrm{TC}-1$ tumor-challenged mice vaccinated with E7-expressing or wild-type vaccinia. (A) Representative luminescence images of TC-1 tumor-challenged mice receiving adoptive transfer of E7T-LUC cells. C57BL/6 mice (five per group) were subcutaneously challenged with $1 \times 10^{4}$ TC-1 tumor cells per mouse via the right hind leg. One week after tumor challenge, the tumor-bearing mice received E7T-LUC cells at a dose of $5 \times 10^{6}$ cells per mouse via the tail vein. One week after adoptive transfer of E7T-LUC cells, the treated mice were vaccinated with wild-type (Wt) vaccinia (middle) or Vac-sig/E7/LAMP-1 vaccinia (right), or were not vaccinated (left). Mice were imaged with the IVIS imaging system 200 series. Bioluminescence signals were acquired for $5 \mathrm{~min}$. (B) Line graph depicting kinetic changes in luminescence imaging over a period of 14 days after TC-1 tumor challenge: treated mice vaccinated with wild-type vaccinia (open squares), treated mice vaccinated with Vac-sig/E7/LAMP-1 vaccinia (solid circles), and treated mice not vaccinated with vaccinia (open diamonds). 
(A)

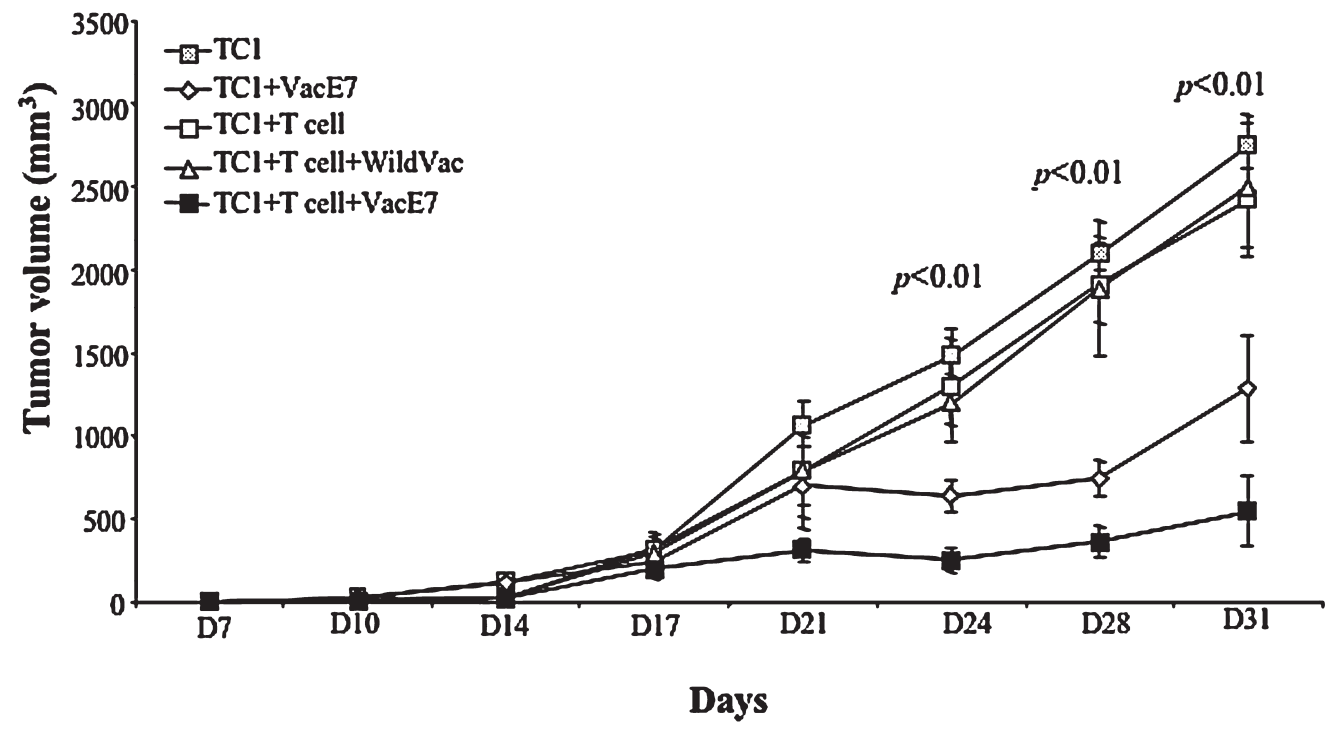

(B)

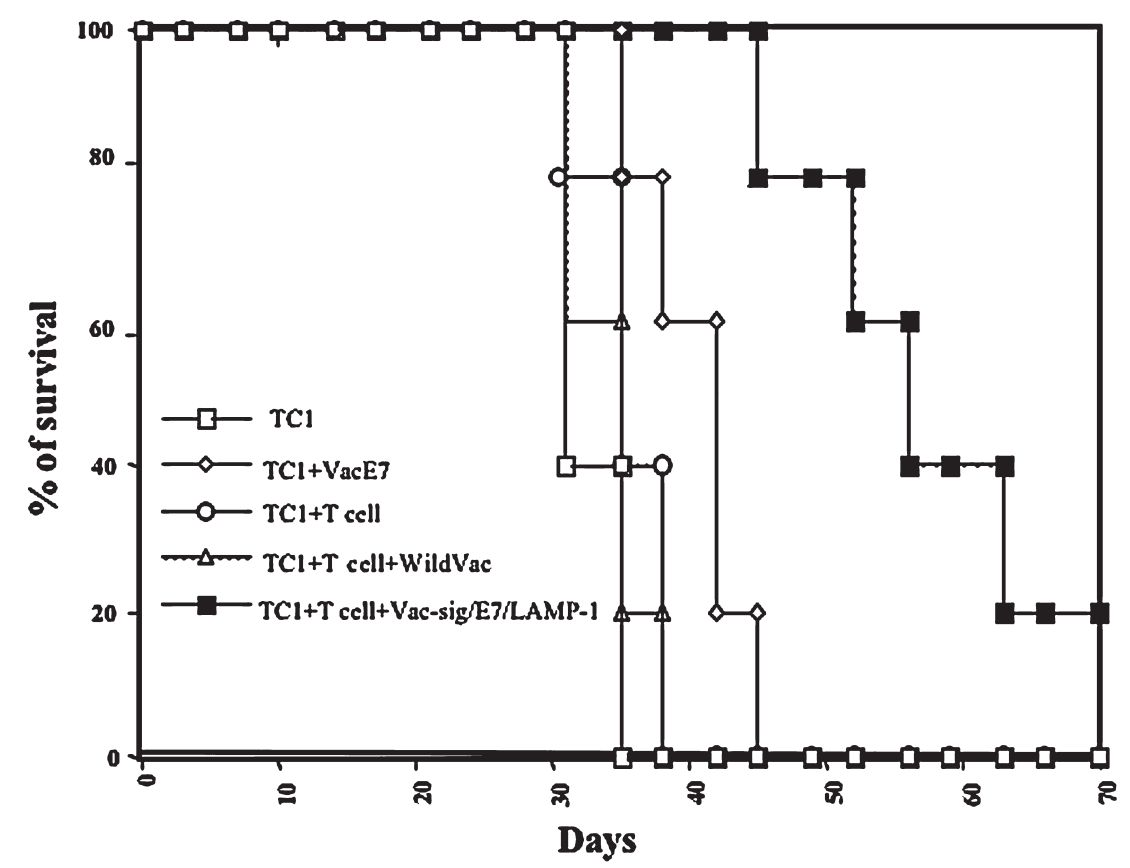

FIG. 6. In vivo tumor treatment experiment in TC-1 tumor-challenged mice treated with E7-specific CD8 ${ }^{+} \mathrm{T}_{\text {cells }}$ boosted with wild-type vaccinia or Vac-sig/E7/LAMP-1. C57BL/6 mice (five per group) were subcutaneously injected with $1 \times 10^{4}$ TC-1 tumor cells per mouse via the right hind leg. One week after tumor challenge, TC-1 tumor-bearing mice were treated with adoptively transferred E7T-LUC cells at a dose of $5 \times 10^{6}$ cells per mouse via the tail vein. One week after T cell treatment, mice were boosted with either wild-type vaccinia or Vac-sig/E7/LAMP-1 vaccinia. (A) Line graph depicting the tumor volume (mean \pm $\mathrm{SD}$ ) in TC-1 tumor-bearing mice treated with adoptive transfer only (open square), adoptive transfer followed by wild-type vaccinia (open triangle), or adoptive transfer followed by Vac-sig/E7/LAMP-1 (closed square). TC-1 tumor-bearing mice treated with Vac-sig/E7/LAMP-1 alone (open diamond) or without treatment (open square) were used as controls. Tumor volume was measured starting from day 7 after tumor challenge. (B) Kaplan-Meier survival analysis showing long-term survival in TC-1 tumor-bearing mice treated with adoptive transfer only (open square), adoptive transfer followed by wild-type vaccinia (open triangle), or adoptive transfer followed by Vac-sig/E7/LAMP-1 (closed square). TC-1 tumor-bearing mice treated with Vacsig/E7/LAMP-1 alone (open diamond) or without treatment (open square) were used as controls. 
of antigen-specific T cells was boosted by vaccination with antigen-specific dendritic cells (DCs). They found that ACT therapy followed by vaccination with peptide-pulsed DCs resulted in increased tumor infiltration of transferred antigen-specific $\mathrm{T}$ cells and significantly improved antitumor responses. Similarly, in our study, we showed that ACT therapy in conjunction with vaccination with antigen-specific vaccinia increased tumor infiltration by the antigen-specific adoptively transferred $\mathrm{T}$ cells and enhanced the antitumor effect. Thus, effective active vaccination in conjunction with ACT therapy may represent a promising approach for cancer treatment. It may be of interest in future to compare the various vaccination strategies to identify the best active vaccination to boost the ACT therapeutic effect.

Although vaccinia can be used to boost ACT therapy to generate better therapeutic effects, some concerns are associated with its use as a biotherapeutic agent in cancer treatment. For instance, anti-vaccinia antibodies may be present in previously vaccinated cancer patients and prohibit successful vaccination with vaccinia. Many individuals have been previously vaccinated with vaccinia for the eradication of smallpox. These individuals may have preexisting immunity against the vaccinia virus and may not be suitable candidates for treatment with the same kind of vaccinia vector (Hung et al., 2006). One potential solution to alleviate such limitations is to use different poxviruses for the immunotherapy. For example, the Yaba-like disease virus may be suitable as an alternative replicating poxvirus vector for patients who have anti-vaccinia antibodies because it is not influenced by preexisting immunity against the vaccinia virus (Hu et al., 2001).

In summary, our data suggest that treatment by adoptive transfer of antigen-specific $\mathrm{T}$ cells followed by active immunization with vaccinia encoding tumor-specific antigens offers an improved method compared with ACT therapy alone. Our findings have the potential for clinical translation. Furthermore, our data suggest that the employment of luciferase-expressing antigen-specific $\mathrm{T}$ cells in conjunction with noninvasive bioluminescence imaging offers a potentially plausible approach to study the function of $\mathrm{T}$ cells in vivo.

\section{ACKNOWLEDGMENTS}

The authors gratefully acknowledge Archana Monie and Talia Hoory for preparation of the manuscript. This work was supported by NIH grant R24CA92871.

\section{AUTHOR DISCLOSURE STATEMENT}

For all authors, no competing financial interests exist.

\section{REFERENCES}

BORYSIEWICZ, L.K., FIANDER, A., NIMAKO, M., MAN, S., WILKINSON, G.W., WESTMORELAND, D., EVANS, A.S., ADAMS, M., STACEY, S.N., BOURSNELL, M.E., RUTHER-
FORD, E., HICKLING, J.K., and INGLIS, S.C. (1996). A recombinant vaccinia virus encoding human papillomavirus types 16 and 18 , E6 and E7 proteins as immunotherapy for cervical cancer. Lancet 347, 1523-1527.

CHEN, C.H., SUH, K.W., JI, H., CHOTI, M.A., PARDOLL, D.M., and WU, T.C. (2000). Antigen-specific immunotherapy for human papillomavirus 16 E7-expressing tumors grown in the liver. J. Hepatol. 33, 91-98.

CONRY, R.M., ALLEN, K.O., LEE, S., MOORE, S.E., SHAW, D.R., and LOBUGLIO, A.F. (2000). Human autoantibodies to carcinoembryonic antigen (CEA) induced by a vaccinia-CEA vaccine. Clin. Cancer Res. 6, 34-41.

DUDLEY, M.E., and ROSENBERG, S.A. (2003). Adoptive-cell-transfer therapy for the treatment of patients with cancer. Nat. Rev. Cancer 3, 666-675.

DUDLEY, M.E., WUNDERLICH, J., NISHIMURA, M.I., YU, D., YANG, J.C., TOPALIAN, S.L., SCHWARTZENTRUBER, D.J., HWU, P., MARINCOLA, F.M., SHERRY, R., LEITMAN, S.F., and ROSENBERG, S.A. (2001). Adoptive transfer of cloned melanomareactive $T$ lymphocytes for the treatment of patients with metastatic melanoma. J. Immunother. 24, 363-373.

EDER, J.P., KANTOFF, P.W., ROPER, K., XU, G.X., BUBLEY, G.J., BOYDEN, J., GRITZ, L., MAZZARA, G., OH, W.K., ARLEN, P., TSANG, K.Y., PANICALI, D., SCHLOM, J., and KUFE, D.W. (2000). A phase I trial of a recombinant vaccinia virus expressing prostate-specific antigen in advanced prostate cancer. Clin. Cancer Res. 6, 1632-1638.

HORIG, H., LEE, D.S., CONKRIGHT, W., DIVITO, J., HASSON, H., LAMARE, M., RIVERA, A., PARK, D., TINE, J., GUITO, K., TSANG, K.W., SCHLOM, J., and KAUFMAN, H.L. (2000). Phase I clinical trial of a recombinant canarypoxvirus (ALVAC) vaccine expressing human carcinoembryonic antigen and the B7.1 co-stimulatory molecule. Cancer Immunol. Immunother. 49, 504-514.

HU, Y., LEE, J., McCART, J.A., XU, H., MOSS, B., ALEXANDER, H.R., and BARTLETT, D.L. (2001). Yaba-like disease virus: An alternative replicating poxvirus vector for cancer gene therapy. J. Virol. 75, 10300-10308.

HUNG, C.F., TSAI, Y.C., HE, L., COUKOS, G., FODOR, I., QIN, L., LEVITSKY, H., and WU, T.C. (2006). Vaccinia virus preferentially infects and controls human and murine ovarian tumors in mice. Gene Ther. 14, 20-29.

INSTITUTE OF LABORATORY ANIMAL RESEARCH, COMMITTEE ON LIFE SCIENCES, NATIONAL RESEARCH COUNCIL (1996). Guide for the Care and Use of Laboratory Animals. (National Academies Press, Washington, D.C.).

JI, H., CHANG, E.Y., LIN, K.Y., KURMAN, R.J., PARDOLL, D.M., and WU, T.C. (1998). Antigen-specific immunotherapy for murine lung metastatic tumors expressing human papillomavirus type $16 \mathrm{E} 7$ oncoprotein. Int. J. Cancer 78, 41-45.

LEEN, A.M., ROONEY, C.M., and FOSTER, A.E. (2006). Improving $\mathrm{T}$ cell therapy for cancer. Annu. Rev. Immunol. 25, 243-265.

LIN, K.Y., GUARNIERI, F.G., STAVELEY-O'CARROLL, K.F., LEVITSKY, H.I., AUGUST, J.T., PARDOLL, D.M., and WU, T.C. (1996). Treatment of established tumors with a novel vaccine that enhances major histocompatibility class II presentation of tumor antigen. Cancer Res. 56, 21-26.

LOU, Y., WANG, G., LIZEE, G., KIM, G.J., FINKELSTEIN, S.E., FENG, C., RESTIFO, N.P., and HWU, P. (2004). Dendritic cells strongly boost the antitumor activity of adoptively transferred $\mathrm{T}$ cells in vivo. Cancer Res. 64, 6783-6790.

MCANENY, D., RYAN, C.A., BEAZLEY, R.M., and KAUFMAN, H.L. (1996). Results of a phase I trial of a recombinant vaccinia virus that expresses carcinoembryonic antigen in patients with advanced colorectal cancer. Ann. Surg. Oncol. 3, 495-500.

MOSS, B. (1991). Vaccinia virus: A tool for research and vaccine development. Science 252, 1662-1667. 
SANDA, M.G., SMITH, D.C., CHARLES, L.G., HWANG, C., PIENTA, K.J., SCHLOM, J., MILENIC, D., PANICALI, D., and MONTIE, J.E. (1999). Recombinant vaccinia-PSA (PROSTVAC) can induce a prostate-specific immune response in androgen-modulated human prostate cancer. Urology 53, 260-266.

SCHOLL, S.M., BALLOUL, J.M., LE GOC, G., BIZOUARNE, N., SCHATZ, C., KIENY, M.P., VON MENSDORFF-POUILLY, S., VINCENT-SALOMON, A., DENEUX, L., TARTOUR, E., FRIDMAN, W., POUILLART, P., and ACRES, B. (2000). Recombinant vaccinia virus encoding human MUC1 and IL2 as immunotherapy in patients with breast cancer. J. Immunother. 23, 570-580.

WALBOOMERS, J.M., JACOBS, M.V., MANOS, M.M., BOSCH, F.X., KUMMER, J.A., SHAH, K.V., SNIJDERS, P.J., PETO, J., MEIJER, C.J., and MUNOZ, N. (1999). Human papillomavirus is a necessary cause of invasive cervical cancer worldwide. J. Pathol. 189, $12-19$.

WANG, T.L., LING, M., SHIH, I.M., PHAM, T., PAI, S.I., LU, Z., KURMAN, R.J., PARDOLL, D.M., and WU, T.C. (2000). Intramuscular administration of E7-transfected dendritic cells generates the most potent E7-specific anti-tumor immunity. Gene Ther. 7, 726-733.
WU, T.C., GUARNIERI, F.G., STAVELEY-O'CARROLL, K.F., VISCIDI, R.P., LEVITSKY, H.I., HEDRICK, L., CHO, K.R., AUGUST, J.T., and PARDOLL, D.M. (1995). Engineering an intracellular pathway for major histocompatibility complex class II presentation of antigens. Proc. Natl. Acad. Sci. U.S.A. 92, 11671-11675.

Address reprint requests to: Dr. T.-C. Wu

Department of Pathology

School of Medicine, Johns Hopkins University

CRBII Room 309

1550 Orleans Street, Baltimore, MD 21231

E-mail: wutc@jhmi.edu

Received for publication April 5, 2007; accepted after revision May 14, 2007.

Published online: June 15, 2007. 